\title{
Gene expression of tendon markers in mesenchymal stromal cells derived from different sources
}

\author{
Janina Burk ${ }^{1,2^{*}+}$, Claudia Gittel ${ }^{2 \dagger}$, Sandra Heller ${ }^{1,3}$, Bastian Pfeiffer ${ }^{2}$, Felicitas Paebst ${ }^{2}$, Annette B Ahrberg ${ }^{1,4}$
} and Walter Brehm ${ }^{1,2}$

\begin{abstract}
Background: Multipotent mesenchymal stromal cells (MSC) can be recovered from a variety of tissues in the body. Yet, their functional properties were shown to vary depending on tissue origin. While MSC have emerged as a favoured cell type for tendon regenerative therapies, very little is known about the influence of the MSC source on their properties relevant to tendon regeneration.

The aim of this study was to assess and compare the expression of tendon extracellular matrix proteins and tendon differentiation markers in MSC derived from different sources as well as in native tendon tissue. MSC isolated from equine bone marrow, adipose tissue, umbilical cord tissue, umbilical cord blood and tendon tissue were characterized and then subjected to mRNA analysis by real-time polymerase chain reaction.
\end{abstract}

Results: MSC derived from adipose tissue displayed the highest expression of collagen $1 \mathrm{~A} 2$, collagen $3 \mathrm{~A} 1$ and decorin compared to MSC from all other sources and native tendon tissue $(p<0.01)$. Tenascin- $C$ and scleraxis expressions were highest in MSC derived from cord blood compared to MSC derived from other sources, though both tenascin- $C$ and scleraxis were expressed at significantly lower levels in all MSC compared to native tendon tissue $(p<0.01)$.

Conclusions: These findings demonstrate that the MSC source impacts the cell properties relevant to tendon regeneration. Adipose derived MSC might be superior regarding their potential to positively influence tendon matrix reorganization.

Keywords: MSC, Mesenchymal stromal cell, Tendon, Adipose tissue, Bone marrow, Umbilical cord, Collagen, Decorin, Scleraxis, Tenascin-C

\section{Background}

Tendon disease is a common cause of acute pain and long-term mobility loss in athletes and elderly patients [1-4]. Due to the predominantly degenerative character of the disease, in many cases, regeneration following acute injury cannot be achieved by conventional therapies [1-4]. Cell-based therapies, however, were shown to have positive effects on tendon regeneration not only in

\footnotetext{
* Correspondence: burk@rz.uni-leipzig.de

${ }^{\dagger}$ Equal contributors

'Translational Centre for Regenerative Medicine (TRM), University of Leipzig, Philipp-Rosenthal-Strasse 55, 04103 Leipzig, Germany

${ }^{2}$ Large Animal Clinic for Surgery, Faculty of Veterinary Medicine, University of Leipzig, An den Tierkliniken 21, 04103 Leipzig, Germany

Full list of author information is available at the end of the article
}

small animal studies, but also in the equine large animal model [5-8].

Multipotent mesenchymal stromal cells (MSC) are currently the most frequently used cell type in tendon therapy based on their functions as connective tissue cell progenitors and potent immunomodulators $[9,10]$. However, cells that correspond to the general definition of MSC can be found in many different locations in the body, and several studies showed that important differences exist between MSC derived from different sources [11-16]. Thus, it is to be expected that the MSC source also has an impact on the success of the clinical use of the cells. In order to be able to choose the optimal cell source, more knowledge is required on cell characteristics 
that are specifically important for the intended therapeutic application.

Aiming at regenerative tendon therapies, it is important to consider that tendons are composed of mainly extracellular matrix with a strictly hierarchical organization of collagen fibrils [4,17]. The re-organization of these fibrils and other extracellular matrix components after injury is crucial for regaining the mechanical load capacity of the tendon and thus to prevent re-injury. MSC application was shown to improve the extracellular matrix structure of damaged tendons and increased the collagen 1 content towards normal levels [6,7], leading to the assumption that replacement and remodelling of the extracellular matrix is a major contribution of MSC to tendon healing. Aiming to apply MSC that best possibly support the extracellular matrix remodelling, it appears of great importance to know the extent of the expression of tendon extracellular matrix components in MSC from different tissue sources.

Therefore, in this study, it was aimed to further extend and support our previous data on the comparative characterization of equine MSC from different sources $[13,18]$. For this purpose, MSC derived from different tissue origins were used for a comparative assessment of their gene expression levels of molecules that are relevant to tenogenesis and to the composition and structure of tendon extracellular matrix. Cells were isolated from equine bone marrow $(\mathrm{BM})$, adipose tissue ( $\mathrm{AT})$, tendon tissue (TT), umbilical cord blood (UCB) and umbilical cord tissue (UCT). Cells from all samples were subjected to MSC characterization assays and to real-time reversetranscription polymerase chain reaction (RT-PCR) analyses of collagen $1 \mathrm{~A} 2$, collagen $3 \mathrm{~A} 1$, decorin, tenascin- $\mathrm{C}$ and scleraxis expression. Native tendon tissue controls (naT) were used as a reference for the gene expression analyses.

\section{Results}

\section{Basic MSC characteristics}

Plastic-adherent cells could be isolated from all samples. The cells were capable of adipogenic, osteogenic and chondrogenic differentiation as confirmed by Oil Red O, von Kossa or Alcian blue staining, respectively. Flow cytometry revealed that they expressed CD29 and CD44, and lacked expression of CD34, CD45 and MHCII, although there were some variations between the percentages of positive cells between donors and MSC sources (data published elsewhere [18]).

\section{Collagen expression}

AT-MSC displayed a distinctively high collagen 1A2 expression, which differed significantly from MSC derived from all other sources or from naT $(\mathrm{p}<0.01)$. BM- and UCT-MSC collagen 1A2 expression was overall lowest. Although at a lower level than collagen 1A2, AT-MSC also showed the highest collagen 3A1 expression, which was significant compared to all other sample types $(\mathrm{p}<0.01)$ except for UCB-MSC. Correspondingly, the ratio of collagen 1A2 expression to collagen 3A1 expression was higher in AT-MSC than in MSC derived from all other sources or in naT $(\mathrm{p}<0.01)$. BM-MSC displayed the lowest ratio ( $\mathrm{p}<0.01$ compared to AT-MSC, TT-MSC and naT) (Figure 1 and Additional file 1: Figure S1, Table 1).

\section{Decorin expression}

Decorin expression was generally higher in all MSC than in naT, with the highest expression levels in AT- and TT-MSC ( $\mathrm{p}<0.01$ compared to naT and BM-MSC). Of all MSC sources, UCB-MSC displayed the lowest decorin expression ( $\mathrm{p}<0.01$ compared to AT-, TT- and UCTMSC), with one single UCB-MSC sample showing an outstandingly low expression (Figure 1 and Additional file 1: Figure S1, Table 1).

\section{Tenascin- $\mathrm{C}$ and scleraxis expression}

Tenascin- $\mathrm{C}$ and scleraxis expression levels were both significantly higher in naT than in MSC, irrespective of their source $(\mathrm{p}<0.01)$. For tenascin-C expression, no significant differences between MSC from different sources were found. Moreover, tenascin- $C$ was expressed at overall lower levels than the other genes investigated. For scleraxis, differences were also evident between MSC from different sources, with the highest median expression in UCB-MSC ( $\mathrm{p}<0.01$ compared to BM- and UCT-MSC) (Figure 1 and Additional file 1: Figure S1, Table 1).

\section{Discussion}

In this study, we showed that significant differences exist between the gene expression of tendon extracellular matrix components in MSC derived from different sources, which is of potential relevance for MSC application in tendon therapy.

Most remarkably, there was a clear pattern that ATMSC expressed the extracellular matrix proteins collagen 1A2, collagen 3A1 and decorin at highest levels. In contrast, collagen expression was low in BM- and UCT-MSC. Furthermore, the ratio of collagen 1A2 to collagen 3A1 was highest in AT-MSC and lowest in BM- and UCT-MSC. Collagen 1A2 is the most abundant protein in healthy tendon tissue, while collagen $3 \mathrm{~A} 1$ is also present but higher quantities are only found during tendon repair $[4,17]$. Decorin is the most abundant proteoglycan in tendon tissue and plays an important role in the regulation of the collagen fibril structure and cell proliferation as well as in stimulating immune responses [19]. MSC which highly express these important extracellular matrix proteins may therefore have the best potential to positively influence matrix reorganization during tendon healing. 


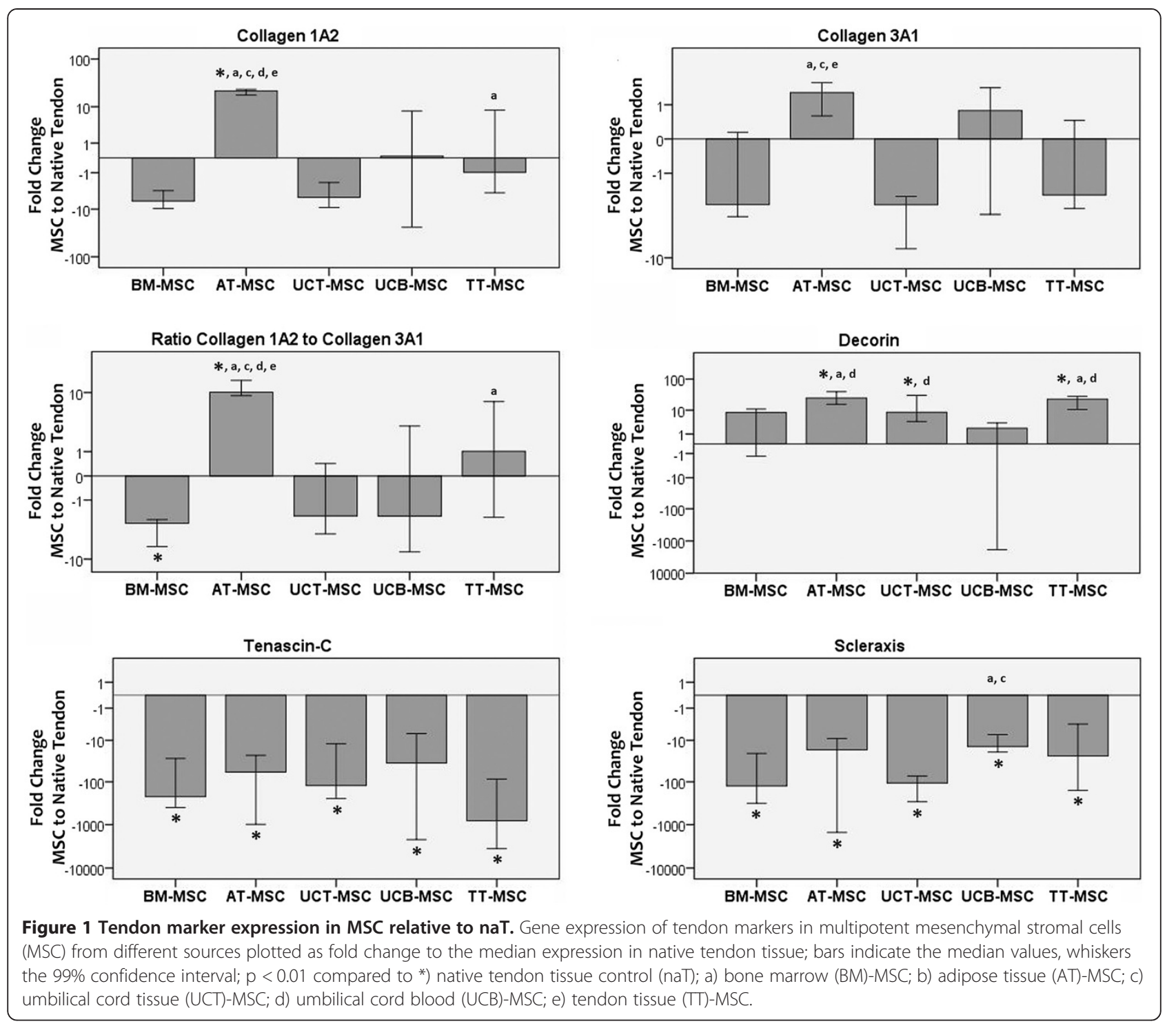

Table 1 Tendon marker expression levels in MSC and naT

\begin{tabular}{|c|c|c|c|c|c|c|}
\hline & \multicolumn{6}{|c|}{ Target gene expression ratios (median (interquartile range)) } \\
\hline & Collagen $1 \mathrm{~A} 2$ & Collagen $3 \mathrm{~A} 1$ & $\begin{array}{l}\text { Collagen } 1 \mathrm{~A} 2 / \\
\text { collagen } 3 \mathrm{~A} 1\end{array}$ & Decorin & Tenascin-C & Scleraxis \\
\hline BM-MSC & $0,0322(0,0306)$ & $0,4163(0,3440)$ & $0,1066(0,0225)$ & $0,8936(0,2955)$ & $0,0006(0,0006)$ & $0,0112(0,0230)$ \\
\hline AT-MSC & $3,9673(0,7435)^{*}, a, c, d, e$ & $1,6649(0,2418)^{*}, a, c, e$ & $2,2667(0,3658) *{ }^{*}, \mathrm{a}, \mathrm{c}, \mathrm{d}, \mathrm{e}$ & $2,4893(1,4706)^{*}, \mathrm{a}, \mathrm{d}$ & $0,0021(0,0033)$ & $0,0874(0,0896)$ \\
\hline UCT-MSC & $0,0418(0,0364)$ & $0,3971(0,3039)$ & $0,1753(0,0630)$ & $0,8952(0,5497)^{*}, \mathrm{~d}$ & $0,0010(0,0002)$ & $0,0129(0,0031)$ \\
\hline UCB-MSC & $0,1888(1,0578)$ & $1,1562(0,5452)$ & $0,1741(0,6369)$ & $0,2870(0,0270)$ & $0,0034(0,0047)$ & $0,1019(0,0889) a, c$ \\
\hline TT-MSC & $0,2010(0,3445) a$ & $0,5891(0,2539)$ & $0,4111(0,5535)$ a & $2,2928(1,1165)^{*}, \mathrm{a}, \mathrm{d}$ & $0,0001(0,0001)$ & $0,0686(0,1441)$ \\
\hline nat & $0,1735(0,1645)$ & $0,6516(0,7127)$ & $0,2042(0,1226)$ a & $0,0951(0,3832)$ & $\begin{array}{l}0,1176(0,0369) \\
a, b, c, d, e\end{array}$ & $\begin{array}{l}16,5828(1,6803) \\
a, b, c, d, e\end{array}$ \\
\hline
\end{tabular}

Gene expression of tendon markers normalized to ACTB and GAPDH. $\mathrm{P}<0.01$ compared to *) native tendon tissue control (naT); a) bone marrow (BM)-multipotent mesenchymal stromal cells (MSC); b) adipose tissue (AT)-MSC; c) umbilical cord tissue (UCT)-MSC; d) umbilical cord blood (UCB)-MSC; e) tendon tissue (TT)-MSC.

Corresponding data are shown in the additional file (Additional file 1: Figure S1). 
Regarding the expression of tenascin- $\mathrm{C}$ and scleraxis, both genes being expressed at lower levels in MSC than in naT, differences between MSC samples were not as eminent as those between the expression levels of collagens or decorin. Among the MSC derived from different sources, UCB-MSC displayed the highest median expression and AT-MSC the second highest median expression of both tenascin- $\mathrm{C}$ and scleraxis. The glycoprotein tenascin- $\mathrm{C}$ is known to be present in healthy tendon and is involved in the regulation of collagen fibrillogenesis, but is also associated with tendon disease [20,21]. However, although frequently being used as an additional tenogenic differentiation marker [22,23], tenascin- $C$ is expressed in a wide variety of cell types and its upregulation is also associated with non-musculoskeletal diseases such as asthma or cancer [24]. The transcription factor scleraxis is considered to be a more specific tenogenic differentiation marker, as it was found to be essential to tenogenesis, although further signals are required to contribute to tendon development [25-27]. Scleraxis was further shown to regulate collagen $1 \mathrm{~A} 2$ synthesis in cardiac fibroblasts [28] and may therefore also play an important role in the re-organization of the extracellular tendon matrix after injury. However, in the current study using unstimulated MSC, a correlation between scleraxis expression and collagen 1A2 expression was not evident.

For healthy, adult tendon tissue, high expression levels of collagen $1 \mathrm{~A} 2$ and scleraxis and low expression levels of tenascin- $\mathrm{C}$ were previously found to be most specific, while cultured tenocytes displayed a significantly lower scleraxis expression [21]. This is in accordance with the current study, in which scleraxis was expressed at significantly lower levels in all MSC compared to naT, while collagen $1 \mathrm{~A} 2$ and collagen $3 \mathrm{~A} 1$ expression by monolayer-cultured MSC, except for AT-MSC, did not differ significantly from naT. This supports the hypothesis that scleraxis is a useful marker to distinguish undifferentiated fibroblast-like cells and fully differentiated tenocytes.

Our findings also correspond with a previously published study in which rat BM- and TT-MSC were compared regarding their properties relevant to tendon regeneration [29]. In this study, TT-MSC displayed superior properties and a higher expression of tendon markers compared to BM-MSC [29]. While in the current study, tendon marker expression in TT-MSC was also higher than in BM-MSC, AT-MSC diplayed an even higher marker expression than TT-MSC. Therefore, based on the hypothesis that re-organization and replacement of the extracellular matrix is a major contribution of MSC to tendon healing, AT may be the most promising cell source for tendon therapy.

There are further aspects which could have an influence on therapeutic success in tendon therapy. Besides practical issues such as the required cell numbers and the optimal way of applying the cells, MSC properties such as their viability and their immunomodulatory capacity are of potential importance. Previous studies showed that differences between equine MSC from different sources also exist with regard to their viability and proliferation potential, at which AT-MSC have already been shown to be superior compared to MSC derived from other sources $[13,15]$. In contrast, no major differences between equine MSC from different sources could be detected with regard to their influence on lymphocyte proliferation and cytokine expression [30], indicating a similar immunomodulatory potential.

Taking into consideration their ease of harvest, high viability and good immunomodulatory potential as well as their high expression of tendon extracellular matrix components as demonstrated in the current study, ATMSC appear to display several advantages for clinical use in tendon therapy.

However, the current study is of preliminary character. Comparative studies of MSC from different sources using in vitro models that mimic tenogenic conditions [31] may help to further substantiate our hypothesis. Eventually, it remains to be investigated whether a high expression of extracellular matrix proteins in vitro finally leads to the intended results in terms of replacement and re-organization of the extracellular matrix after in vivo application.

\section{Conclusions}

The current study demonstrates that MSC from different sources display different tendon marker expression patterns, particularly with respect to the most important tendon extracellular matrix components. As improvement in matrix re-organization has been shown to be the major beneficial effect of MSC in tendon therapy, this finding is of potential clinical relevance. AT-MSC showed the highest expression of tendon extracellular matrix components and may therefore be most potent to positively influence extracellular matrix re-organization after tendon injury.

\section{Methods}

\section{Sample collection}

For primary cell isolation, UCB and UCT were recovered from healthy foals and BM, AT and $\mathrm{TT}$ were recovered from healthy adult horses (age range: 3-18 years), as described previously [13] and with approval by the local ethics committee (Landesdirektion Leipzig, Germany, A13/10). Further tendon samples were collected from the superficial digital flexor tendons of animals which had been euthanized for unrelated reasons and immediately stored at $-80^{\circ} \mathrm{C}$ to be used as the naT reference for RNA analysis.

\section{Cell culture and characterization}

Cells were isolated by density gradient centrifugation from BM and UCB and by collagenase I digestion from 
Table 2 Primer sequences

\begin{tabular}{|c|c|c|c|c|}
\hline Equine gene & Forward primer & Reverse primer & Accession number & PCR product in bp \\
\hline$\overline{A C T B}$ & ATCCACGAAACTACCTTCAAC & CGCAATGATCTTGATCTTCATC & NM_001081838.1 & 174 \\
\hline GAPDH & TGGAGAAAGCTGCCAAATACG & GGCCTITCTCCTTCTCTTGC & NM_001163856.1 & 309 \\
\hline Collagen $1 \mathrm{~A} 2$ & CAACCGGAGATAGAGGACCA & CAGGTCCTTGGAAACCTTGA & XM_001492939.1 & 243 \\
\hline Collagen $3 \mathrm{~A} 1$ & AGGGGACCTGGTTACTGCTT & TCTCTGGGTTGGGACAGTCT & XM_001917620.2 & 216 \\
\hline Decorin & ACCCACTGAAGAGCTCAGGA & GCCATTGTCAACAGCAGAGA & NM_001081925.2 & 239 \\
\hline Tenascin-C & TCACATCCAGGTGCTTATTCC & CTAGAGTGTCTCACTATCAGG & XM_001916622.2 & 163 \\
\hline Sleraxis $_{\text {nat }}$ & TACCTGGGTTTTCTTCTGGTCACT & TATCAAAGACACAAGATGCCAGC & NM_001105150.1 & 51 \\
\hline Scleraxis $_{\text {MSC }}$ & AGAGAAAGTTGAGCAAGGACC & TCAAAGACACAAGATGCCAGC & NM_001105150.1 & 294 \\
\hline
\end{tabular}

Primer sequences used for real-time reverse transcription polymerase chain reaction.

AT, TT and UCT as described previously [13]. They were then seeded into culture flasks in low glucose $(1 \mathrm{~g} / \mathrm{L})$ Dulbecco's modified eagle medium (Life Technologies $\mathrm{GmbH}$ ) supplemented with 20\% fetal bovine serum (Sigma Aldrich, Taufkirchen, Germany), 1\% penicillin-streptomycin (PAA Laboratories $\mathrm{GmbH}$, Coelbe, Germany) and 0.1\% gentamycin (Life Technologies $\mathrm{GmbH}$ ), and incubated at $37^{\circ} \mathrm{C}, 95 \%$ humidity and $5 \% \mathrm{CO}_{2}$ for selection of plasticadherent cells and their further expansion. Passage 3 cells were used to confirm their trilineage differentiation potential into adipocytes, osteoblasts and chondrocytes [13], as well as for the assessment of surface marker expression by flow cytometry [18].

\section{RNA analysis}

Five samples of UCB-MSC and 6 samples of each BM-, AT-, TT- and UCT-MSC (passage 3) as well as naT were subjected to RNA analysis by real-time RT-PCR.

Total RNA of MSC was isolated using the RNeasy ${ }^{\circ}$ Mini Kit (Qiagen, Hamburg, Germany) according to instructions of manufacturers (protocol version 09/2010). Frozen naT samples were sliced in $12 \mu \mathrm{m}$ sections with a microtome CM $3050 \mathrm{~S}$ equipped with cryochamber (Leica Microsystems, Wetzlar, Germany) and incubated for $60 \mathrm{~min}$ at $55^{\circ} \mathrm{C}$ in homogenization buffer (15 mM HEPES, $2.5 \mathrm{mM} \mathrm{KCl}, 68.5 \mathrm{mM} \mathrm{NaCl}, 450 \mu \mathrm{M} \mathrm{Na}_{2} \mathrm{HPO}_{4}, 17.5 \mathrm{mM}$ EDTA, $27.5 \mathrm{mM}$ glucose at $\mathrm{pH}$ 7) containing $100 \mu \mathrm{g} / \mathrm{ml}$ proteinase K (Ambion ${ }^{\circ}$ Life Technologies, Darmstadt, Germany). To homogenize the sample, lyzed tendon tissue was passed through a 20-gauge needle several times. Total RNA of tendon tissue homogenate was purified with phe$\mathrm{nol} /$ chloroform extraction and isopropanol precipitation.

DNase-treated RNA was reverse transcribed using the RevertAid H Minus First Strand cDNA Synthesis Kit (Thermo Fisher Scientific, Dreieich, Germany) or the Omniscript RT Kit (Qiagen) with oligo-dT18 primers as described by the manufacturers. Relative quantification of cDNA was performed with a 7500 Real Time PCR System (Applied Biosystems, Foster City, USA) and SYBR ${ }^{\circ}$ Green as double-strand DNA-specific dye $\left(\mathrm{iQ}^{\mathrm{m}} \mathrm{SYBR}^{\circ}\right.$ Green Supermix, Bio-Rad Laboratories, Hercules, USA). Primers amplifying the respective genes are listed in Table 2 and corresponding $\mathrm{Ct}$ values were used to analyze gene expression. RT-PCR analysis of scleraxis expression was performed with two different primer sets for native tendon tissue and isolated MSC. To confirm that relative quantification of both sample types was comparable, expression of scleraxis in MSC derived from BM, AT, UCT, UCB and TT was analyzed using both primer sets. Obtained data showed that relative expression of scleraxis was similar in MSC derived from different sources irrespective of the primer set used (data not shown). Therefore, scleraxis mRNA expression levels of all samples can be compared.

Primer efficiency $\left(E_{\text {gene }}\right)$ was calculated after serial dilution of template cDNA and target gene expression levels were normalized to the reference genes ACTB and GAPDH as described previously [32]:

$$
\text { ratio }=\frac{\sqrt{\left(E_{\text {ref }_{A C T B}}\right)^{C t} \times\left(E_{\text {ref }}{ }_{\text {GAPDH }}\right)^{C t}}}{\left(E_{t \text { arget }}\right)^{C t}}
$$

Further, fold changes (FC) of MSC gene expression compared to naT gene expression were calculated from the normalized gene expression ratios:

$$
\begin{aligned}
& \mathrm{FC}_{\text {increase }}=\left(\text { ratio }_{\text {MSC sample }} / \text { median rationaT }_{\text {naT }}\right)-1 \\
& \mathrm{FC}_{\text {decrease }}=1 /\left(\text { ratio }_{\text {MSC sample }} / \text { median ratio }_{\text {naT }}\right)-1
\end{aligned}
$$

\section{Statistical analysis}

Kruskall-Wallis one way analyses of variance and subsequent Mann-Whitney-U tests were performed to analyze differences between the normalized gene expression levels of the sample groups. $\mathrm{P}<0.01$ was considered as significant.

\section{Additional file}

Additional file 1: Figure S1. Tendon marker expression levels in MSC and naT. Gene expression of tendon markers in multipotent mesenchymal stromal cells (MSC) from different sources and in native tendon tissue (naT), given as ratios normalized to ACTB and GAPDH. BM: bone marrow; AT: adipose tissue; UCB: umbilical cord blood; UCT: umbilical cord tissue; TT: tendon tissue. 


\section{Abbreviations}

MSC: Multipotent mesenchymal stromal cell(s); BM: Bone marrow; AT: Adipose tissue; TT: Tendon tissue; UCB: Umbilical cord blood; UCT: Umbilical cord tissue; naT: Native tendon tissue control; RT-PCR: Reverse-transcription polymerase chain reaction; FC: Fold change(s)

\section{Competing interests}

The authors declare that they have no competing interests.

\section{Authors' contributions}

JB and CG conceived of the study and the study design, coordinated the study, performed part of the cell culture and characterization and were responsible for data analysis and drafting of the manuscript. SH contributed to the study design, performed RT-PCR analyses and participated in data analyses and drafting of the manuscript. BP contributed to the study design and performed RT-PCR analyses. FP carried out part of the cell culture and characterization and the respective data analyses. AA and WB contributed to the study design and coordination. All authors critically revised the manuscript and approved the final version.

\section{Acknowledgements}

The authors acknowledge Prof. A. Bader and Prof. P. Seibel for kindly providing the laboratory facilities (Center for Biotechnology and Biomedicine, University of Leipzig), and further Prof. Dr. C. Kasper, Dr. I. Ribitsch and Prof. Dr. C. Staszyk for providing their support. The work presented in this paper was made possible by funding from the German Federal Ministry of Education and Research (BMBF 1315883). The work was further funded by the Mehl-Muelhens Foundation and the Dres. Jutta \& Georg Bruns Foundation.

\section{Author details}

${ }^{1}$ Translational Centre for Regenerative Medicine (TRM), University of Leipzig, Philipp-Rosenthal-Strasse 55, 04103 Leipzig, Germany. ${ }^{2}$ Large Animal Clinic for Surgery, Faculty of Veterinary Medicine, University of Leipzig, An den Tierkliniken 21, 04103 Leipzig, Germany. ${ }^{3}$ Tulane University, Department of Pathology and Laboratory Medicine, 1430 Tulane Avenue, New Orleans, Louisiana 70112, USA. ${ }^{4}$ Department of Orthopedics, Traumatology and Plastic Surgery, University of Leipzig, Liebigstrasse 20, 04103 Leipzig, Germany.

Received: 25 October 2014 Accepted: 12 November 2014 Published: 20 November 2014

\section{References}

1. Kader D, Saxena A, Movin T, Maffulli N: Achilles tendinopathy: some aspects of basic science and clinical management. Br J Sports Med 2002, 36:239-249.

2. Scott A, Huisman E, Khan K: Conservative treatment of chronic Achilles tendinopathy. CMAJ 2011, 183:1159-1165.

3. Heckman DS, Gluck GS, Parekh SG: Tendon disorders of the foot and ankle, part 2: achilles tendon disorders. Am J Sports Med 2009, 37:1223-1234.

4. Riley G: Tendinopathy-from basic science to treatment. Nat Clin Pract Rheumatol 2008, 4:82-89.

5. Young RG, Butler DL, Weber W, Caplan Al, Gordon SL, Fink DJ: Use of mesenchymal stem cells in a collagen matrix for Achilles tendon repair. J Orthop Res 1998, 16:406-413.

6. Schnabel LV, Lynch ME, van der Meulen MC, Yeager AE, Kornatowski MA Nixon AJ: Mesenchymal stem cells and insulin-like growth factor-I gene-enhanced mesenchymal stem cells improve structural aspects of healing in equine flexor digitorum superficialis tendons. J Orthop Res 2009, 27:1392-1398.

7. Crovace A, Lacitignola L, Rossi G, Francioso E: Histological and immunohistochemical evaluation of autologous cultured bone marrow mesenchymal stem cells and bone marrow mononucleated cells in collagenase-induced tendinitis of equine superficial digital flexor tendon. Vet Med Int 2010, 2010:250978.

8. Godwin EE, Young NJ, Dudhia J, Beamish IC, Smith RK: Implantation of bone marrow-derived mesenchymal stem cells demonstrates improved outcome in horses with overstrain injury of the superficial digital flexor tendon. Equine Vet J 2012, 44:25-32.

9. Yagi H, Soto-Gutierrez A, Parekkadan B, Kitagawa Y, Tompkins RG, Kobayashi N, Yarmush ML: Mesenchymal stem cells: mechanisms of immunomodulation and homing. Cell Transplant 2010, 19:667-679.

10. Caplan Al, Bruder SP: Mesenchymal stem cells: building blocks for molecular medicine in the 21st century. Trends Mol Med 2001, 7:259-264.
11. Yoshimura H, Muneta T, Nimura A, Yokoyama A, Koga H, Sekiya I: Comparison of rat mesenchymal stem cells derived from bone marrow, synovium, periosteum, adipose tissue, and muscle. Cell Tissue Res 2007, 327:449-462.

12. da Silva Meirelles L, Chagastelles PC, Nardi NB: Mesenchymal stem cells reside in virtually all post-natal organs and tissues. J Cell Sci 2006, 119:2204-2213.

13. Burk J, Ribitsch I, Gittel C, Juelke H, Kasper C, Staszyk C, Brehm W: Growth and differentiation characteristics of equine mesenchymal stromal cells derived from different sources. Vet J 2013, 195:98-106.

14. Kern S, Eichler $H$, Stoeve J, Kluter H, Bieback K: Comparative analysis of mesenchymal stem cells from bone marrow, umbilical cord blood, or adipose tissue. Stem Cells 2006, 24:1294-1301.

15. Vidal MA, Walker NJ, Napoli E, Borjesson DL: Evaluation of senescence in mesenchymal stem cells isolated from equine bone marrow, adipose tissue, and umbilical cord tissue. Stem Cells Dev 2012, 21:273-283.

16. lacono E, Brunori L, Pirrone A, Pagliaro PP, Ricci F, Tazzari PL, Merlo B: Isolation, characterization and differentiation of mesenchymal stem cells from amniotic fluid, umbilical cord blood and Wharton's jelly in the horse. Reproduction 2012, 143:455-468.

17. Thorpe $C T$, Clegg PD, Birch HL: A review of tendon injury: why is the equine superficial digital flexor tendon most at risk? Equine Vet J 2010, 42:174-180.

18. Paebst F, Piehler D, Brehm W, Heller S, Schroeck C, Tarnok A, Burk J: Comparative immunophenotyping of equine multipotent mesenchymal stromal cells: an approach toward a standardized definition. Cytometry $A$ 2014, 85:678-687.

19. Yoon JH, Halper J: Tendon proteoglycans: biochemistry and function. J Musculoskelet Neuronal Interact 2005, 5:22-34.

20. Riley GP, Harrall RL, Cawston TE, Hazleman BL, Mackie EJ: Tenascin-C and human tendon degeneration. Am J Pathol 1996, 149:933-943.

21. Taylor SE, Vaughan-Thomas A, Clements DN, Pinchbeck G, Macrory LC, Smith RK, Clegg PD: Gene expression markers of tendon fibroblasts in normal and diseased tissue compared to monolayer and three dimensional culture systems. BMC Musculoskelet Disord 2009, 10:27.

22. Altman GH, Horan RL, Martin I, Farhadi J, Stark PR, Volloch V, Richmond JC, Vunjak-Novakovic G, Kaplan DL: Cell differentiation by mechanical stress. FASEB J 2002, 16:270-272.

23. Kuo CK, Tuan RS: Mechanoactive tenogenic differentiation of human mesenchymal stem cells. Tissue Eng Part A 2008, 14:1615-1627.

24. Brellier F, Tucker RP, Chiquet-Ehrismann R: Tenascins and their implications in diseases and tissue mechanics. Scand J Med Sci Sports 2009, 19:511-519.

25. Schweitzer R, Chyung JH, Murtaugh LC, Brent AE, Rosen V, Olson EN, Lassar A, Tabin CJ: Analysis of the tendon cell fate using Scleraxis, a specific marker for tendons and ligaments. Development 2001, 128:3855-3866.

26. Murchison ND, Price BA, Conner DA, Keene DR, Olson EN, Tabin CJ, Schweitzer R: Regulation of tendon differentiation by scleraxis distinguishes forcetransmitting tendons from muscle-anchoring tendons. Development 2007, 134:2697-2708

27. Berthet E, Chen C, Butcher K, Schneider RA, Alliston T, Amirtharajah M: Smad3 binds Scleraxis and Mohawk and regulates tendon matrix organization. J Orthop Res 2013, 31:1475-1483.

28. Espira L, Lamoureux L, Jones SC, Gerard RD, Dixon IM, Czubryt MP: The basic helix-loop-helix transcription factor scleraxis regulates fibroblast collagen synthesis. J Mol Cell Cardiol 2009, 47:188-195.

29. Tan Q, Lui PP, Rui YF, Wong YM: Comparison of potentials of stem cells isolated from tendon and bone marrow for musculoskeletal tissue engineering. Tissue Eng Part A 2012, 18:840-851.

30. Carrade DD, Lame MW, Kent MS, Clark KC, Walker NJ, Borjesson DL: Comparative analysis of the immunomodulatory properties of equine adult-derived mesenchymal stem cells(). Cell Med 2012, 4:1-11.

31. Raabe O, Shell K, Fietz D, Freitag C, Ohrndorf A, Christ HJ, Wenisch S, Arnold S: Tenogenic differentiation of equine adipose-tissue-derived stem cells under the influence of tensile strain, growth differentiation factors and various oxygen tensions. Cell Tissue Res 2013, 352:509-521.

32. Pfaffl MW: A new mathematical model for relative quantification in real-time RT-PCR. Nucleic Acids Res 2001, 29:e45.

\section{doi:10.1186/1756-0500-7-826}

Cite this article as: Burk et al:: Gene expression of tendon markers in mesenchymal stromal cells derived from different sources. BMC Research Notes 2014 7:826. 